\title{
2 Dimensions Interactive Media Learning of Good Behavior for Children Elementary School
}

\author{
Chaerur Rozikin ${ }^{1}$, Jajam Haerul Jaman ${ }^{2}$, Iqbal Alexander Gumelar ${ }^{3}$ \\ \{chaerur.rozikin@staff.unsika.ac.id ${ }^{1}$, jajam.haeruljaman@staff.unsika.ac.id ${ }^{2}$, \\ iqbal.alexander15074@student.unsika.ac.id ${ }^{3}$ \} \\ Singaperbangsa Karawang University Computer Science Faculty Karawang, Indonesia 1, 2, 3
}

\begin{abstract}
Children are often presented with cartoon shows or animations, two that are not appropriate for their age. There are also many other elements found in children's shows such as violence, common elements and others that make behavior changes in children, children's behavior can develop based on the current spectacle. Lack of parental supervision in sorting children's shows makes children free to watch whatever content they see. Utilization of 2-dimensional animation technology and interactive learning media aims to attract students' interests as behavioral learning as well as entertainment so that children are interested. The methodology used in this research is Multimedia Life Cycle Development (MDLC). This application successfully displays 2-dimensional animation and interactive learning in it. Implementation of this application trial uses paired sample t-test which results in a percentage of significant level $\mathrm{t}$ arithmetic $=$ $10.23>$ value of t table $=(\propto=0.05, d f=29)=1,699$ so that Ho is in the rejection area and $\mathrm{H} 1$ is accepted. Then there are differences between before and after using the application, it can be said that the application can improve student understanding by showing sample data $\overline{x 1}=66.3 \overline{x 2}=82.3$. And also from the results of the calculation of the questionnaire to 30 students using the rating scale to get results $82.3 \%$ of students chose to agree strongly.
\end{abstract}

Keywords: Multimedia, Interactive, 2D, Animations, Education

\section{Introduction}

One crucial component in learning is learning media. The position of the media in education is significant even in line with the learning method because the method used in the learning process will usually require what media can be integrated and adapted to the conditions faced [1].

The animation is one part of the form of the entertainment world in the way of visualization of moving images, whether equipped with audio or not and usually in the form of two-dimensional or three-dimensional images. In connection with the many entertainment programs that are developing at this time, the animation program is one form of program that is very popular with children. So the authors see the prospect in the future that animation programs may be used as material by parents to educate their children, to provide education and excellent entertainment facilities, and useful to help the growth of children's creativity.

Currently, the media used in learning to behave well is only in the form of books and blackboards without using teaching aids so that students become less interested and quickly feel bored. To the address problems above, the writer tries to provide alternatives, so that they 
can be used as a reference for learning and entertainment that reliable. For that, we need a media that is simple, easy to understand, and easy to obtain. With the above conclusions, it is appropriate to use visual media, especially animation and interactive learning media, to convey the message to be transmitted. Because with animation and interactive learning media delivery will be faster and easier to attract children's interests. Because the world of children is a world full of colors, so most children will prefer entertainment that has an animated pattern compared to a show that is really like a soap opera or something else. Because in the world of animation many new characters or characters, unique, funny, and settings that are different from real life will be found so that it is hoped that it will stimulate the creativity of children so that they can develop towards better children's behavior.

\section{Literature Review}

The media comes from the Latin Medius, which means middle, intermediary or introduction. In Arabic, the media is an intermediary or introduction to the message from the sender to the recipient of the word. The Association for Education and Communication Technology (AECT) defines media as all forms that are used for a process of information distribution.

Learning media are media that include tools, which are physically used to convey the contents of teaching material, which consists of books, tape recorders, films, slides (picture frames), photos, pictures, graphics, television, and computers.

Multimedia is divided into two types, namely interactive multimedia and linear multimedia. Interactive multimedia is multimedia that can be operated by its users and can provide feedback, whereas linear multimedia is the opposite.

A cartoon film is a moving image that comes from a collection of various objects explicitly arranged so that it moves according to a predetermined path at any time count. The purpose in question is a picture of humans, text writing, pictures of animals, pictures of plants, buildings, and so forth.

\section{Research Methodology}

The research methodology used in designing, building, and implementing interactive learning media application procedures for good behavior is the Multimedia Development Life Cycle (MDLC). The research resulted in a multimedia application product equipped with supporting tools. Which will be implemented at SDN Adirasa Barat IV and also with the stages of Multimedia Development Life Cycle (MDLC) as Figure 1 [2]. 


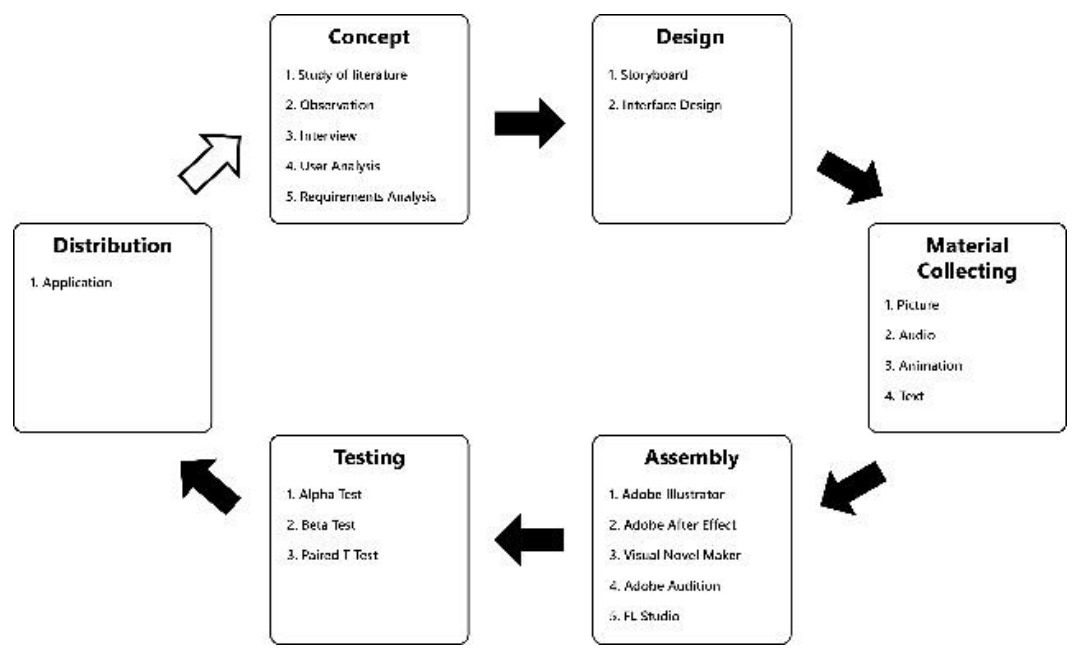

Fig. 1. Research Design.

\section{Result and Discussion}

\subsection{Storyboard design}

Storyboard navigation design in Figure 2.

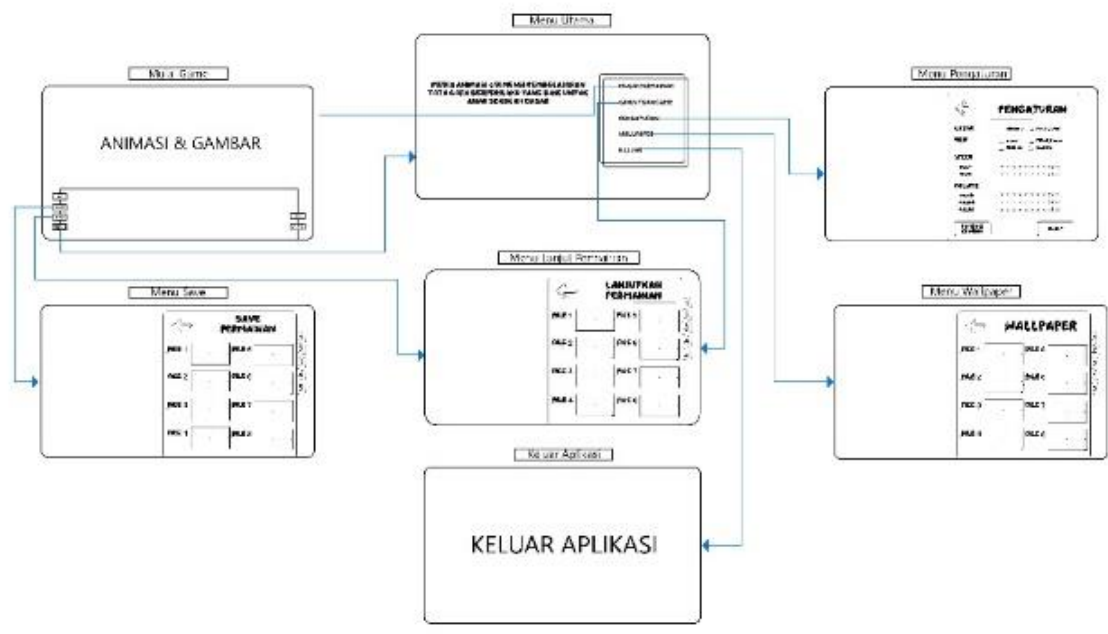

Fig. 2. Storyboard Navigation Design. 


\subsection{Interface design}

Main menu interface is Figure 3.

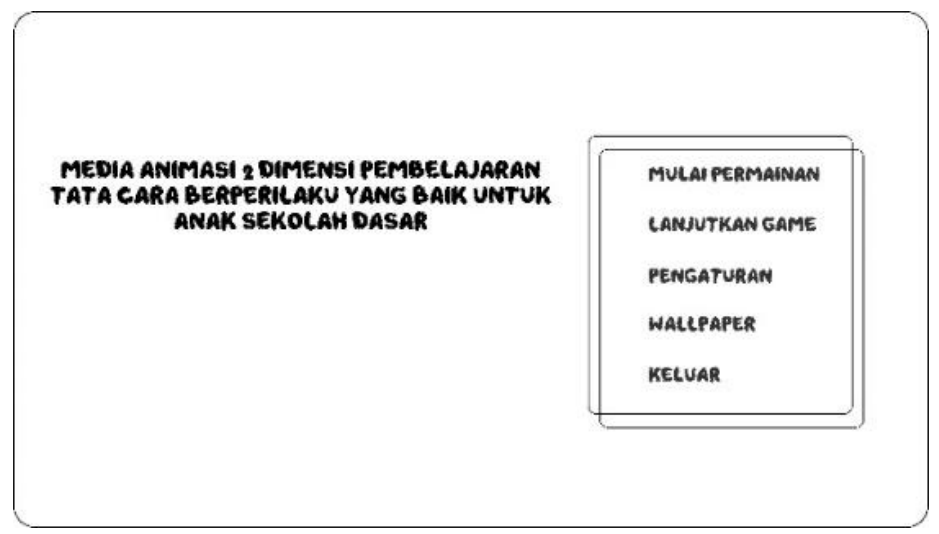

Fig. 3. Main Menu Interface

Start game interface is Figure 4.

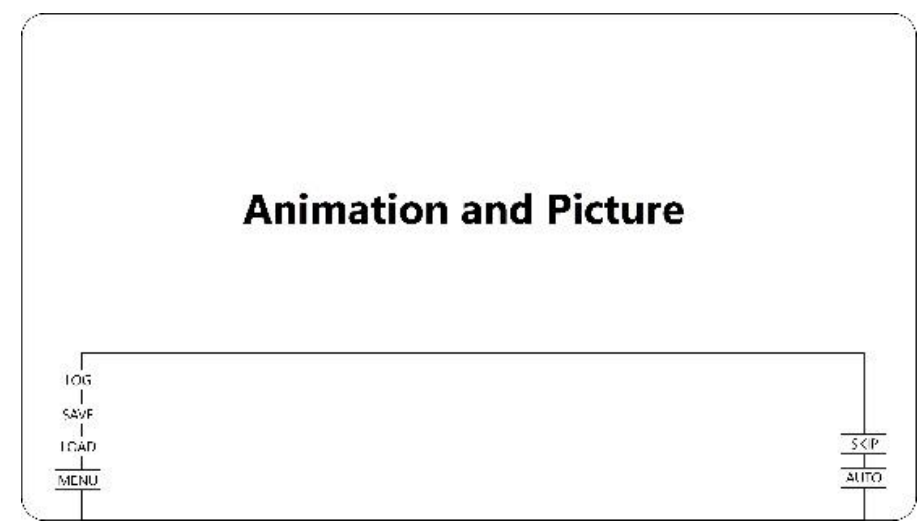

Fig. 4. Start Game Interface.

After following the stages of the methodology in the Multimedia Development Life Cycle (MDLC). Then the next test is carried out which aims to find out the shortcomings and also the level of satisfaction felt by application users, while the testing carried out is alpha and beta testing.

\subsection{Alpha testing}

Done to find out if the functional error of the software has been running as expected, as will be done, namely:

a. Testing the menu buttons, sub menus, and exit buttons.

b. Testing appear options when the animation takes place. 
c. Testing the choice of questions during the animation.

Table 1 is Fuctionality Testing.

Table 1. Functionality Testing.

\begin{tabular}{|c|c|c|c|}
\hline No & Test Component & Test Item & Result \\
\hline \multirow{5}{*}{1} & \multirow{5}{*}{ Main Menu Application } & $\begin{array}{l}\text { Selecting the Game Start } \\
\text { Button }\end{array}$ & Ok \\
\hline & & $\begin{array}{l}\text { Selecting Continue Game } \\
\text { Button }\end{array}$ & $\mathrm{Ok}$ \\
\hline & & Select the Settings Button & Ok \\
\hline & & Select Button Wallpaper & $\mathrm{Ok}$ \\
\hline & & Select the Exit Button & Ok \\
\hline 2 & Save the game & Save progress on the game & Ok \\
\hline 3 & Question Interface & Display Questions & Ok \\
\hline 4 & Question Choice & Choosing Questions & Ok \\
\hline
\end{tabular}

\subsection{Beta testing}

The questionnaire was conducted to 30 respondents, namely grade 6 students of SD Adiarsa Barat IV. To measure whether the application can be used as a learning medium for good behavior or not, the questionnaire uses a Likert scale and rating scale. Questionnaire results for students is Figure 5.

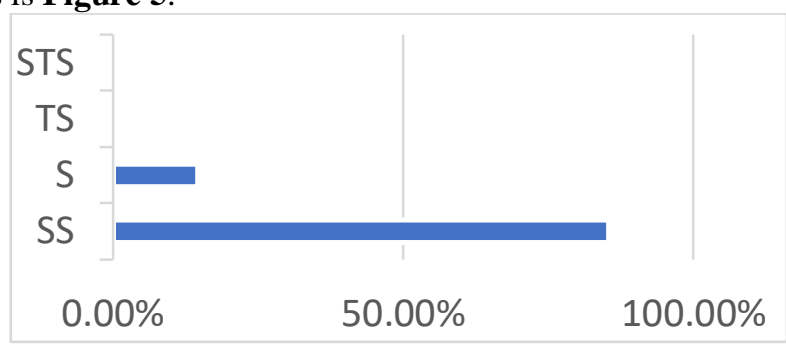

Fig. 5. Percentage of Student Questionnaire Results.

For the results of questionnaire scores conducted on students obtained results $87.4 \%$ of students chose to agree strongly or in the rating scale received a score of 1162 , which is between 900 to 1200 which means that student respondents rate that strongly agrees that the application can be used as a defensive medium. The following questionnaire scores in the form of a rating scale. Figure 6 is Results with rating scale. 


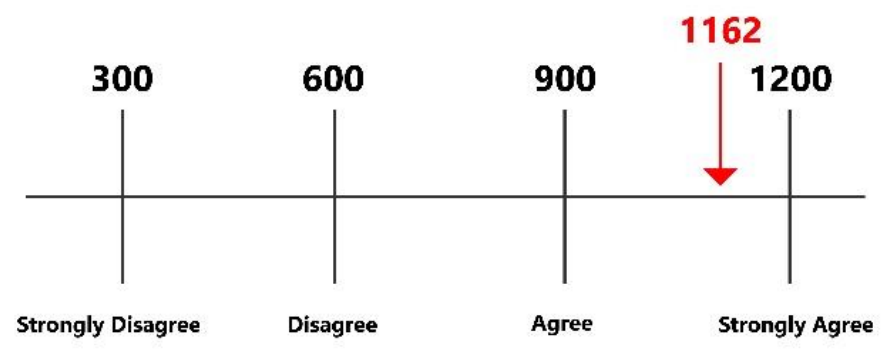

Fig. 6. Results with rating scale (Students).

\subsection{Matched T test}

Trials were conducted on students by taking a sample of one class that is 30 students using a paired test by looking at the value of the evaluation results between before and after using interactive learning media applications for good behavior, then look for the difference values and calculate the average by Equation (1).

$$
D=x 2-x 1
$$

$$
\text { Average }=\frac{\sqrt{D}}{n}
$$

Information :

$\mathrm{x} 1=$ value before using the form

$\mathrm{x} 2=$ evaluate after using the application

$\mathrm{n}=$ number of samples

After that the standard deviation is calculated using the formula in Equation (2) :

$$
\begin{aligned}
& S=\sqrt{\frac{1}{n-1}\left\{\sum D^{2} \frac{\left(\Sigma D^{2}\right)}{n}\right\}} \\
& S=\sqrt{\frac{1}{30-1}\left\{9800 \frac{(\Sigma 480)^{2}}{30}\right\}} \\
& S=\sqrt{\frac{1}{29}\left\{9800 \frac{230400}{30}\right\}} \\
& S=\sqrt{\frac{1}{29}\{9800-7680\}} \\
& S=\sqrt{\frac{1}{29}\{2120\}} \\
& S=\sqrt{73,10}=8.55
\end{aligned}
$$


So we get the t-value of Equation (3):

$$
\mathrm{T}_{\text {hitung }}=\frac{\frac{\Sigma D}{n}}{\frac{s}{\sqrt{n}}}=\frac{\frac{480}{30}}{\frac{8.55}{\sqrt{30}}}=\frac{16}{1.563}=10.23
$$

After that you can see the value of $t$ table for comparison, $t$ table can be seen in the following way:

$$
\begin{aligned}
\mathrm{t} \propto & =\mathrm{t}_{0,05(\mathrm{df})} & & \mathrm{df}=\mathrm{n}-1 \\
& =\mathrm{t}_{0,05(37)} & & \mathrm{df}=30-1 \\
& =1.699 & & =29
\end{aligned}
$$

Distribution T-Chart in Figure 7.

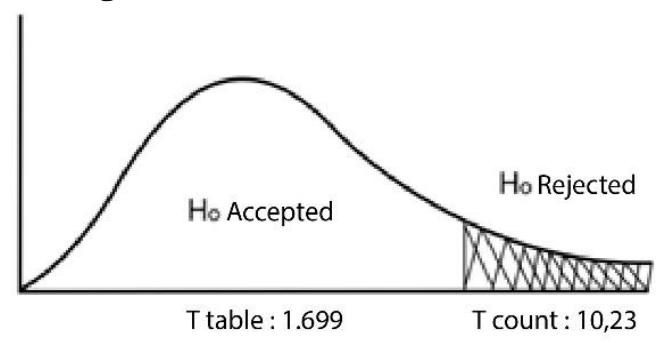

Fig. 7. Distribution t-Chart[3].

a. $\mathrm{H}_{0}: \mu_{1}=\mu_{2}$ (Conditions where there is no significant difference between before and after using interactive learning media applications for good behavior).

b. $\mathrm{H}_{1}: \mu_{1}<\mu_{2}$ Conditions where $\mathrm{H}_{\mathrm{o}}$ is rejected, then there is a significant difference between before and after using interactive learning media applications for good behavior).

c. Hypothesis testing is based on $\mathrm{T} / \mathrm{t}$-test :

- $\mathrm{H}_{0}$ is accepted if $\mathrm{t}_{\text {count }} \leq \mathrm{t}$-table

- $\mathrm{H}_{0}$ is rejected if $\mathrm{t}_{\text {count }}>\mathrm{t}$-table

From the calculation results, it is known the value of t-count $>\mathrm{t}$-table so that $\mathrm{H}_{0}$ is rejected, and it can be concluded that "there are significant differences in the results before and after using interactive learning media applications for right behavior procedures where student understanding increases after using interactive learning media applications how to behave correctly"

\section{Conclusions and Recommendations}

\section{Conclusions}

Based on the research that has been carried out, there are several conclusions as follows:

1. Interactive learning media procedures for good behavior as learning media for SDN Adiarsa Barat IV students using the Adobe Illustrator (Demo Version), Adobe After Effect CC 2017 (Demo Version) application and Visual Novel Maker 
(Demo Version) successfully created using the Multimedia Development Life Cycle (MDLC) methodology.

2. Based on the results of the application of this application, the learning outcomes of students at SDN Adiarsa Barat IV are more improved than before using this application. This is evidenced based on the results of paired t-test which shows that the t-count $(10.23)$ is higher than the t-table $(1,699)$ which means there is an increase between before and after using the application and attract students' interest in learning to behave using learning media interactive procedures for good behavior.

\section{Recommendations}

Based on the results of the research conducted, there are several suggestions as a reference for further research as follows:

1. Add new characters that are more funny, cute, and interesting.

2. Add new episodes to add more stories.

3. You are adding so that the application can be played on the Android platform.

4. Adding for download in the Play store.

\section{References}

[1] Arifin, Z., \& Setiyawan, A.: Pengembangan Pembelajaran Aktif dengan ICT. Yogyakarta: PT. Skripta Media Creative (2012)

[2] Agustina, C.: Pengembangan Media Pembelajaran Teknik Animasi 2 Dimensi Berbasis Adobe Flash Untuk Siswa Kelas XI Multimedia di SMK Muhammadiyah Prambanan (2015)

[3] Erdinaya, L. K., \& Ardianto, E.: komunikasi Massa Suatu Pengantar. Bandung: PT Remaja Rosdakarya (2004) 